\title{
Arc-Expressing Neuronal Ensembles Supporting Pattern Separation Require Adrenergic Activity in Anterior Piriform Cortex: An Exploration of Neural Constraints on Learning
}

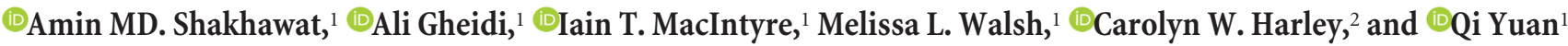 \\ ${ }^{1}$ Division of Biomedical Sciences, Faculty of Medicine, and ${ }^{2}$ Department of Psychology, Faculty of Science, Memorial University of Newfoundland, St. \\ John's, Newfoundland A1B 3V6, Canada
}

\begin{abstract}
Arc ensembles in adult rat olfactory bulb (OB) and anterior piriform cortex (PC) were assessed after discrimination training on highly similar odor pairs. Nonselective $\alpha$ - and $\beta$-adrenergic antagonists or saline were infused in the OB or anterior PC during training. $\mathrm{OB}$ adrenergic blockade slowed, but did not prevent, odor discrimination learning. After criterion performance, Arc ensembles in anterior piriform showed enhanced stability for the rewarded odor and pattern separation for the discriminated odors as described previously. Anterior piriform adrenergic blockade prevented acquisition of similar odor discrimination and of $\mathrm{OB}$ ensemble changes, even with extended overtraining. Mitral and granule cell Arc ensembles in OB showed enhanced stability for rewarded odor only in the saline group. Pattern separation was not seen in the OB. Similar odor discrimination co-occurs with increased stability in rewarded odor representations and pattern separation to reduce encoding overlap. The difficulty of similar discriminations may relate to the necessity to both strengthen rewarded representations and weaken overlap across similar representations.
\end{abstract}

Key words: Arc; norepinephrine; odor discrimination; olfactory bulb; pattern separation; piriform cortex

Significance Statement

We show for the first time that adrenoceptors in anterior piriform cortex $(\mathrm{aPC})$ must be engaged for adult rats to learn to discriminate highly similar odors. Loss of adrenergic activation in olfactory bulb (OB) slows, but does not prevent, discrimination learning. Both increased stability of the rewarded odor representation and increased pattern separation of the rewarded and unrewarded odors in aPC accompany successful discrimination. In the $\mathrm{OB}$, rewarded odors increase in ensemble stability, but there is no evidence of pattern separation. We suggest that the slow acquisition of similar odor discriminations is related to the differing plasticity requirements for increased stability and pattern separation.

\section{Introduction}

In rodents, the olfactory bulb $(\mathrm{OB})$ receives massive adrenergic input from the locus ceruleus (LC) (McLean et al., 1989). Norepinephrine (NE) release in the $\mathrm{OB}$ is critical for associative learning in rat pups (Wilson and Sullivan, 1994; Yuan et al., 2014). In adult rats, increases in OB NE are associated with improved signal-to-noise ratios (de Almeida et al., 2015) and lower thresholds for odor discriminations (Escanilla et al., 2010) and

\footnotetext{
Received July 15, 2015; revised Aug. 25, 2015; accepted Sept. 8, 2015.

Author contributions: Q.Y. designed research; A.M.S., A.G., I.T.M., and M.L.W. performed research; A.M.S. analyzed data; A.M.S., C.W.H., and Q.Y. wrote the paper.

This work was supported by the Canadian Institutes of Health Research (Operating Grant MOP-102624) and the Natural Sciences and Engineering Research Council of Canada (Discovery Grant 418451-2013) to Q.Y.

The authors declare no competing financial interests.

Correspondence should be addressed to Dr. Qi Yuan, Division of Biomedical Sciences, Faculty of Medicine, Memorial University of Newfoundland, St. John's, Newfoundland A1B 3V6, Canada. E-mail: qi.yuan@med.mun.ca. DOI:10.1523/JNEUROSCI.2690-15.2015

Copyright $\odot 2015$ the authors $\quad 0270-6474 / 15 / 3514070-06 \$ 15.00 / 0$
}

appear to be necessary for learning similar odor discriminations (Doucette et al., 2007; Mandairon et al., 2008).

OB mitral cells demonstrate sparse coding and temporally dynamic firing in awake rodents (Rinberg et al., 2006; Wachowiak et al., 2013). Even at this early stage, OB processing is shaped by experience and context. Mitral cell firing patterns diverge for rewarded and unrewarded odors in mice undergoing discrimination training (Doucette and Restrepo, 2008). Mitral cells synchronize firing for rewarded odors and adrenergic blockade disrupts this synchrony and similar odor discrimination (Doucette et al., 2011). Synchronized mitral cell firing increases the likelihood of driving piriform target neurons (Franks and Isaacson, 2006).

Piriform cortex (PC) receives direct projections from $\mathrm{OB}$ via the lateral olfactory tract and is proposed as a critical site for integrating odor features into odor objects (Wilson and Sullivan, 2011). PC pyramidal cells exhibit sparse and diffuse coding to odor input (Stettler and Axel, 2009; Poo and Isaacson, 2011; 
Shakhawat et al., 2014a). In addition, PC pyramidal cells project back to $\mathrm{OB}$ and shape mitral cell responses to odors (Boyd et al., 2015; Otazu et al., 2015). PC itself receives extensive NE input from the LC (Shipley and Ennis, 1996). In rat pups, anterior PC (aPC) odor-NE pairings are sufficient to induce odor preference learning (Morrison et al., 2013). In adult rats, PC LC-NE appears to sharpen odor representations (Bouret and Sara, 2002).

How altered OB signaling after NE neuromodulation influences cortical processing and, vice versa, how cortical changes feedback to influence odor ensemble representation in the $\mathrm{OB}$ have not been characterized experimentally. Here, we examine $\mathrm{OB}$ or aPC ensemble representation in adult rats after a similar odor discrimination task with adrenoceptor blockade in aPC or $\mathrm{OB}$, respectively. We found changes in odor encoding index learning success and that aPC adrenergic blockade prevents learning of a similar odor discrimination.

\section{Materials and Methods}

Subjects. Sixty Sprague Dawley rats (Charles River Laboratories), 8-10 weeks old of both sexes, were subjects. Rats were housed under a $12 \mathrm{~h}$ light/dark cycle with ad libitum dry food and water, except during training. Water deprivation was implemented $4-5 \mathrm{~d}$ before training began with either ad libitum water $1 \mathrm{~h} / \mathrm{d}$ or a total volume of $25 \mathrm{ml} / \mathrm{d}$. Water deprivation was maintained during training. Procedures were consistent with Canadian Council of Animal Care guidelines and were approved by the Memorial University Institutional Animal Care Committee.

Odorants. Odorant solution $(10 \mathrm{ml}$, in mineral oil) was freshly prepared for each experiment. Odors were $1 \%$ of orange versus $2 \%$ of peppermint or $0.001 \%$ of 1 -heptanol versus $0.001 \%$ 1-heptanol +1 -octanol (50:50 mixture; Sigma-Aldrich) (Escanilla et al., 2010; Shakhawat et al., 2014a).

Go/no-go odor discrimination training and drug infusions. Odor discrimination training was performed in a custom-built, computercontrolled four-channel Knosys olfactometer.

Initial rule learning. Orange odor $\left(\mathrm{S}^{+}\right)$was introduced with water reward ( $30 \mu \mathrm{l}$ drop/lick). Each trial lasted $2.5 \mathrm{~s}$. Rats were allowed $0.5 \mathrm{~s}$ to sample the odor and 2.0 s to make a decision. Rats either licked the water port for a minimum of 6 times for reward or rejected the odor by removing their snouts from the port. Intertrial intervals were $5 \mathrm{~s}$. Initially rats underwent $\sim 100$ reinforcement trials per day for $3 \mathrm{~d}$.

Rats were then exposed to the same $\mathrm{S}^{+}$odor while a negative peppermint odor $\left(\mathrm{S}^{-}\right)$not paired with water reward was introduced. Blocks were 20 trials in which $10 \mathrm{~S}^{+}$and $10 \mathrm{~S}^{-}$odors were randomly delivered. Rats completed 5-10 blocks per day until criterion was reached within a block on a given day. The percentages of correct responses to both odors were calculated by software (BBC Basic) and converted to percentages (correct $\mathrm{S}^{+}$response \# + correct $\mathrm{S}^{-}$response \#)/20 $\times 100$. Discrimination learning was defined as $\geq 80 \%$ correct responses in one block. All rats learned to discriminate between the 2 odors within 3-4 blocks (data not shown). After rule learning, ad libitum water was reinstated. The next day, all rats underwent $\mathrm{OB}$ or aPC cannulation surgery and had an $\sim 1$ week recovery.

Cannula implantation. Guide cannulae were custom made by anchoring two stainless steel tubes (23 gauge) to a dental acrylic base. Rats were anesthetized with a ketamine $(100 \mathrm{mg} / \mathrm{kg}$, i.p. $)$ and xylazine $(10 \mathrm{mg} / \mathrm{kg}$, i.p.) mixture and secured in a stereotaxic apparatus. Two holes were drilled $+8.0 \mathrm{~mm}$ anterior and $\sim 1.5 \mathrm{~mm}$ bilateral relative to bregma for $\mathrm{OB}$ or $+2.5 \mathrm{~mm}$ anterior, $\sim 4.0 \mathrm{~mm}$ bilateral for aPC. Guide cannulae were inserted ventral to skull surface at $2.0 \mathrm{~mm}$ for $\mathrm{OB}$ and $6.0 \mathrm{~mm}$ for aPC. Guide cannulae were attached by dental cement to two skull screws.

Similar odor discrimination training and drug infusion. After recovery, rats were infused with vehicle or a mixture of adrenoreceptor antagonists before each training session. For the antagonist mixture, the nonselective $\alpha$-adrenoreceptor antagonist phentolamine hydrochloride (SigmaAldrich, $10 \mathrm{~mm}$ ) and the $\beta$-adrenoreceptor antagonist alprenolol hydrochloride (Tocris Bioscience, $120 \mathrm{~mm}$ ) were dissolved in sterile saline (Mandairon et al., 2008). Three microliters of drug or vehicle were in- fused bilaterally at a rate of $1.0 \mu \mathrm{l} / \mathrm{min}$ via a multisyringe pump $20 \mathrm{~min}$ before training.

Training on the similar odor discrimination problem (1-heptanol vs 1-heptanol + 1-octanol 50:50 mixture) followed the procedures described for orange versus peppermint. Rats were trained over days until criterion was achieved in a block or for a fixed number of blocks if the criterion was not achieved.

Tissue collection. Twenty-four hours after similar odor discrimination training, rats were placed in a sealed container, ventilated with a continuous flow of charcoal-filtered air for 1.5-2 h, and given two 5 min episodes of odor delivery (either $\mathrm{S}^{+}$twice or $\mathrm{S}^{+}$followed by $\mathrm{S}^{-}$) in the same container. The two episodes were separated by $20 \mathrm{~min}$. Immediately after the second episode, rats were killed under isoflurane anesthesia and brains were collected and flash frozen in 2-methylbutane immersed in an ethanol/dry ice-slurry. Brains were kept at $-80^{\circ} \mathrm{C}$.

During sectioning, the right hemispheres of 4-6 rats were arranged side by side in a custom-made plastic box filled with OCT medium in a cryostat at $-20^{\circ} \mathrm{C}$ to form a frozen block. Saline and drug groups were matched in each block. Coronal sections $(20 \mu \mathrm{m})$ were collected on 3 -aminopropyltriethoxysilane (2\%) treated slides. Five to six representative slides over the rostral-to-caudal range of the $\mathrm{OB}$ and aPC were chosen for FISH and stored at $-20^{\circ} \mathrm{C}$.

FISH. Full-length Arc riboprobes conjugated to digoxigenin were extracted using a commercial transcript kit (Ambion). The purity and integrity of synthesized riboprobes were ensured by a mini quickspin RNA column (Roche Diagnostics). Two microliters of the probe was tested via gel electrophoresis before use.

Brain slides were thawed for 10-15 min at room temperature and quickly fixed in $4 \%$ paraformaldehyde. The slides were bathed in acetic anhydride and treated in 1:1 methanol/acetone solution at $-20^{\circ} \mathrm{C}$. The slides were then incubated for $60 \mathrm{~min}$ in prehybridization buffer in a humid chamber. Next, the slides were incubated overnight with $100 \mathrm{ng}$ of Arc probe in a hybridization oven at $56^{\circ} \mathrm{C}$. All solutions were made in DEPC (Sigma-Aldrich)-treated water $(0.1 \%)$. The next day, slides were washed in a series of saline-sodium citrate buffer, treated with RNase A at $37^{\circ} \mathrm{C}$, submerged in $2 \% \mathrm{H}_{2} \mathrm{O}_{2} / \mathrm{SSC}$ buffer solution, blocked with normal sheep serum, and incubated with anti-digoxigenin-horseradish peroxidase antibody (Roche Diagnostics) overnight at $4^{\circ} \mathrm{C}$. The slides were labeled with Cy3 (1:50) using a TSA labeling kit (PerkinElmer) and cell nuclei were counterstained with 4'-6-diamidino-2-phenylindole (DAPI; Sigma-Aldrich). Finally, sections were coated with Vectashield antifade medium, coverslipped, and sealed with nail polish.

Image acquisition and analysis. Tissue damage from cannulation prevented examination of the cannulated structure, but here we address the influence on the projection structure. All slides were scanned in a Fluoview FV1000 confocal microscope (Olympus; Shakhawat et al., 2014a). Images of aPC were taken at $20 \times$ magnification (one medial and one lateral region; Fig. $1 A$ ) and images of $\mathrm{OB}$ at $40 \times$ (two dorsolateral and two ventromedial regions; Fig. $2 A$ ). The photomultiplier tube assignments, confocal aperture size, and contrast remained constant for each slide. The $z$-stacks (optical thickness: $1.0 \mu \mathrm{m}$ ) throughout the thickness of the section $(20 \mu \mathrm{m})$ were acquired from 3-4 slides for each animal.

ImageJ software was used for counting cells in the scanned images. Cell labeling (foci, cytoplasmic, double, and DAPI) was done manually and was achieved by checking the multiple optical sections (20\% mid-range of $z$-stack) that comprised each cell (Shakhawat et al., 2014a). Average cell counts of all regions in the $\mathrm{OB}$ or aPC from all slides in the same animals were reported.

Statistics. OriginPro 9.0 software was used to analyze all datasets. Student's $t$ tests between the saline- and drug-infused groups were used for statistical comparisons. Data are presented as mean \pm SEM.

\section{Results}

OB adrenoceptor blockade impairs similar odor discrimination learning, reliability of rewarded odor representations, and pattern separation in aPC

We first tested whether blocking $\mathrm{OB}$ adrenoceptors has any effect on similar odor discrimination learning. $\beta$ - and $\alpha$-adrenoceptor block- 
A
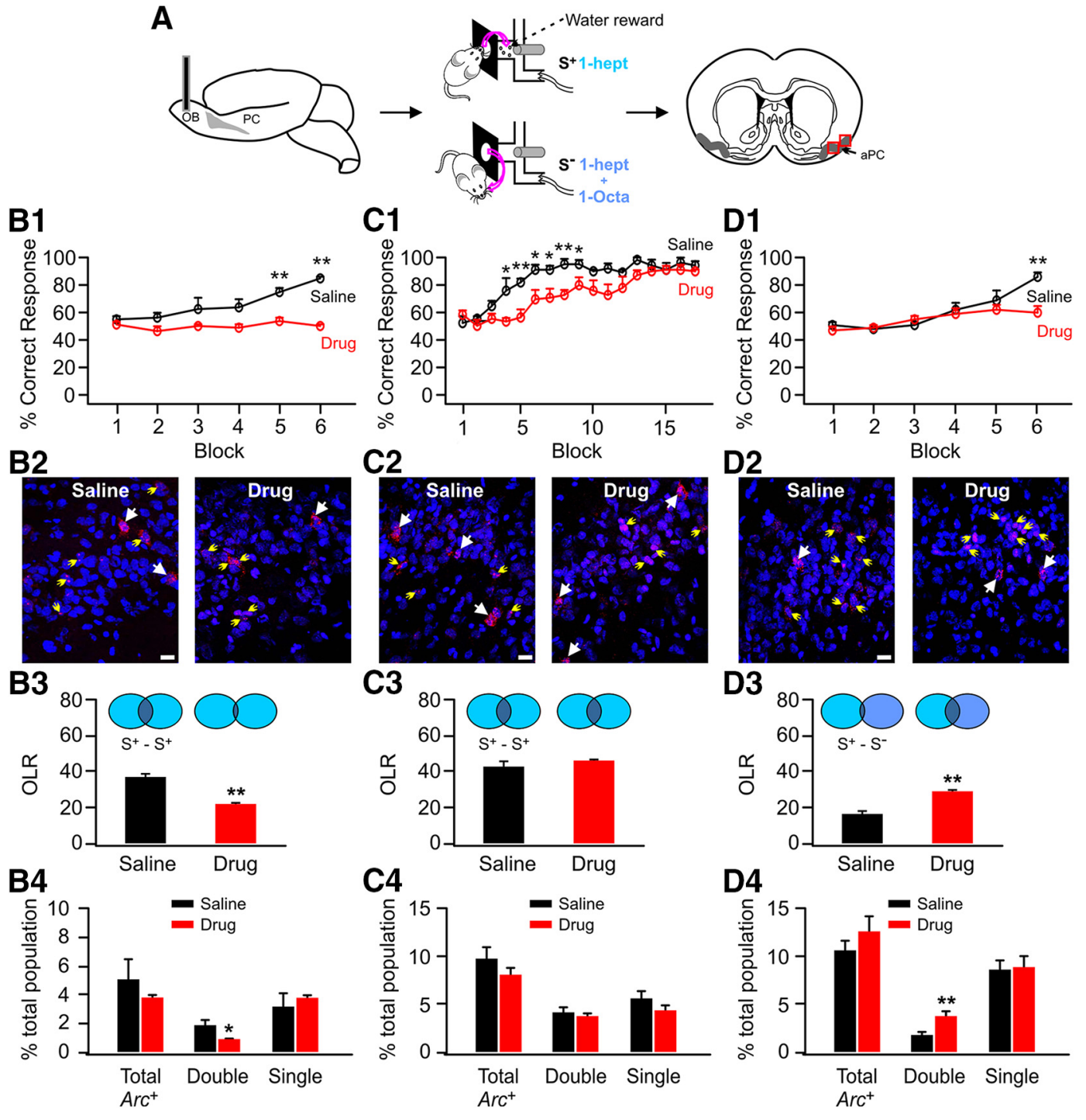

C1

$\underbrace{+}_{1-O c t a}$

Figure 1. OB adrenoceptor blockade slows similar odor discrimination learning and pattern separation in the aPC. $\boldsymbol{A}$, Schematic of experimental procedures. B1-B4, Impaired odor discrimination by adrenoceptor blockade is accompanied by reduced reliability of pyramidal cell activity. $\boldsymbol{B 1}$, Correct responses in the drug and saline groups after six blocks of training. $\boldsymbol{B 2}$, Example images of Arc $^{+}$

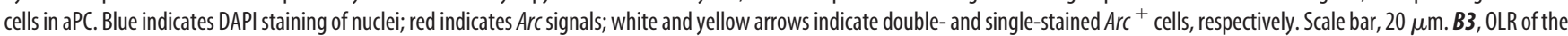
two ensembles to the same reward odor $\left(S^{+}\right)$in the drug and saline groups. B4, Distribution of $\operatorname{Arc}^{+}$cells including total, double-stained, and single-stained cells. ${ }^{*} p<0.05$; ${ }^{* *} p<0.01$. C1-C4, Prolonged training leads to odor discrimination in adrenoceptor-blocked group and restores reliability of pyramidal cell activity. D1-D4, Impaired odor discrimination by adrenoceptor blockade is accompanied by reduced pattern separation between rewarded $\left(S^{+}\right)$and unrewarded $\left(S^{-}\right)$ensembles.

ade slowed discrimination learning of highly similar odor pairs. The saline-infused group learned to discriminate the $\mathrm{S}^{+}$and $\mathrm{S}^{-}$odors in 6 blocks ( $84 \pm 1.25 \%$ success rate), whereas the drug group was unable to discriminate after 6 blocks $(49 \pm 1.25 \%, n=4 ; t=19.80$, $p=1.08 \mathrm{E}^{-6}$; Fig. 1B1,C1,D1). However, extended training eventually led to successful discrimination in the drug group. By 14 blocks of training, the drug group showed significant discrimination $(88 \pm$ $2.55 \%)$ and was no different from the saline group $(92 \pm 4.06 \%, n=$ $5 ; t=0.83, p=0.43$; Fig. 1C1).

To investigate the effect of $\mathrm{OB}$ adrenergic blockade on odor representations in the aPC, we looked at Arc expression in rats that were exposed either to the $\mathrm{S}^{+}$odor twice or to the $\mathrm{S}^{+}$followed by the $\mathrm{S}^{-}$. Arc mRNA is expressed in the nucleus of the cell shortly ( $\sim 5 \mathrm{~min})$ after an odor stimulation and is translocated into the cytoplasm $\sim 20-30 \mathrm{~min}$ later. Therefore, nucleus and cytoplasm double-labeled $\mathrm{Arc}^{+}$cells after repeated exposures to the same odor indicate those that are reliably activated by the odor, whereas double-labeled $\mathrm{Arc}^{+}$cells after two different odor episodes are likely those activated by both odors and index the correlation of the two odors (Shakhawat et al., 2014a).

The overlap ratio (OLR), defined by the percentage of double $\mathrm{Arc}^{+}$cells over total $\mathrm{Arc}^{+}$cells, was used to measure the reliability of odor representations to the rewarded odor in the aPC after two consecutive $\mathrm{S}^{+}$episodes. At the sixth block, when the salineinfused animals learned to discriminate between $\mathrm{S}^{+}$and $\mathrm{S}^{-}$ whereas the drug group did not, there was a significant difference in the $\mathrm{Arc}^{+}$cell patterns between the two groups. The OLR in the saline group was significantly larger $(37.56 \pm 1.57 \% ; n=4)$ than that in the drug group $\left(22.16 \pm 0.26 \% ; t=9.70, p=6.87 \mathrm{E}^{-5}\right.$; Fig. 1B2,B3). This replicates the finding of increased stability with reward seen previously (Shakhawat et al., 2014a) and suggests that a less stable representation of the $\mathrm{S}^{+}$in the aPC occurs due to $\mathrm{OB}$ adrenergic blockade and is associated with failure to discriminate. The smaller OLR in the drug group was due to fewer double $\mathrm{Arc}^{+}$cells in the aPC $(0.83 \pm 0.39 \%)$ relative to the saline group $(1.85 \pm 0.39 \%, n=4 ; t=2.63, p=0.04$; Fig. $1 B 4)$. 
A

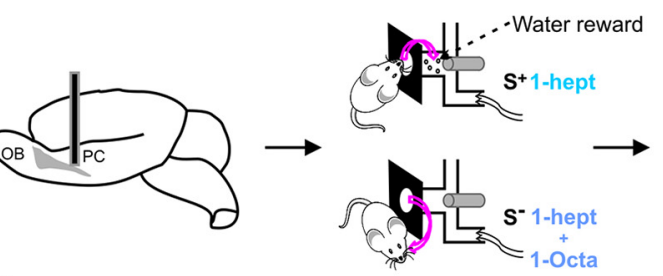

B1
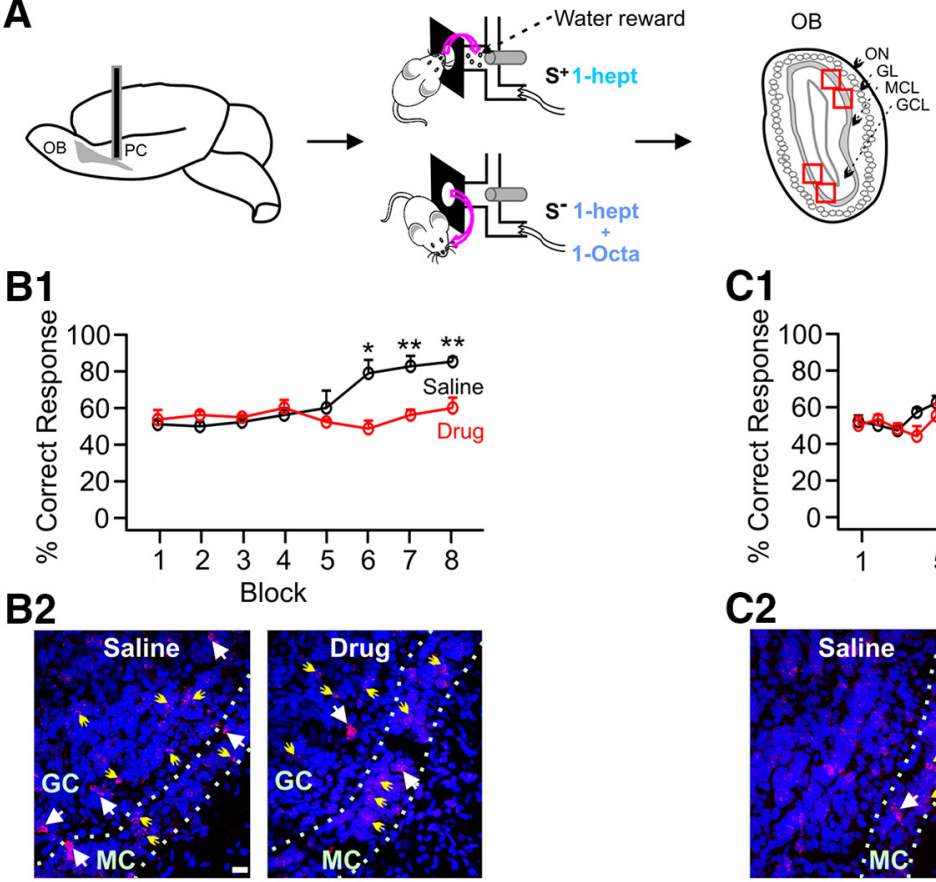

B3

B5

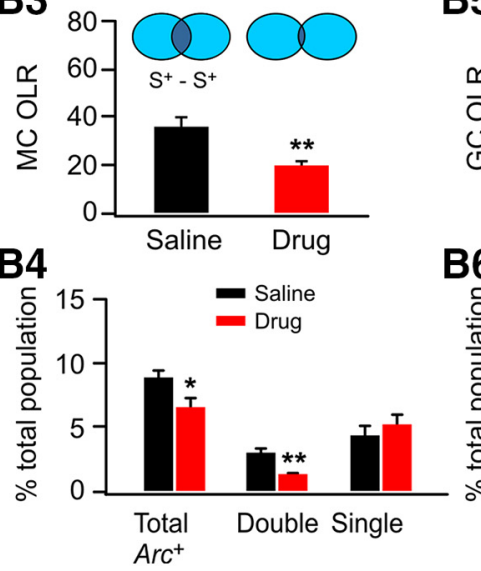

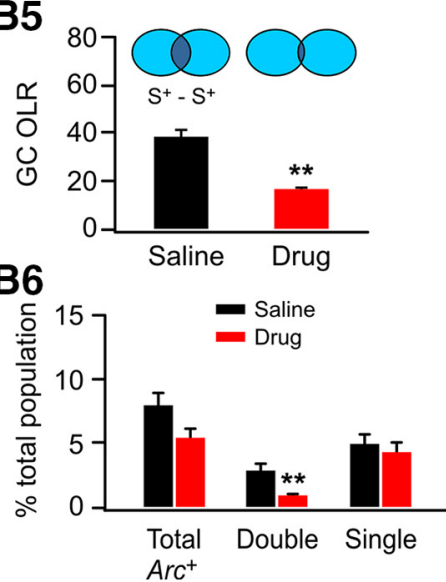

C1

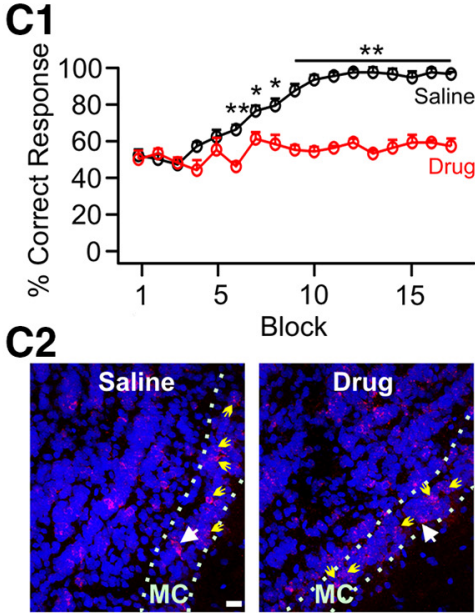

C3

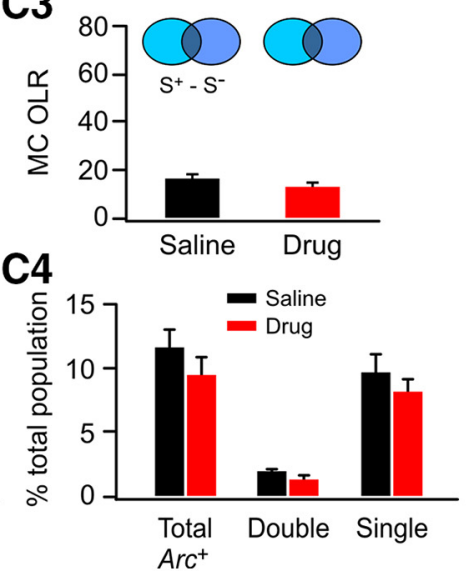

Figure 2. APC adrenoceptor blockade prevents similar odor discrimination learning and changes in 0B odor representations. $\boldsymbol{A}$, Schematic of experimental procedures. $\boldsymbol{B}$ 1- $\mathbf{B} 6$, Impaired odor discrimination by adrenoceptor blockade is accompanied by reduced reliability of mitral and granule cell representations. $\boldsymbol{B}$, Correct responses in the drug and saline group with eight training blocks. B2, Example of Arc $^{+}$cells in the OB. Blue indicates DAPI staining of nuclei; red indicates Arc signals. White and yellow arrows indicate double- and single-stained Arc ${ }^{+}$cells respectively. GC, Granule cell layer; MC, mitral cell layer. Scale bar, $20 \mu \mathrm{m}$. B3, OLR of two mitral cell ensembles to the same reward odor $\left(S^{+}\right)$in the drug and saline groups. B4, Distribution of Arc ${ }^{+}$mitral cells including total, double-stained, and single-stained cells. B5, 0LR of two granule cell ensembles to the same reward odor $\left(S^{+}\right)$in the drug and saline groups. B6, Distribution of $A r C^{+}$granule cells including total, double-stained, and single-stained cells. ${ }^{*} p<0.05 ;{ }^{* *} p<0.01$. C1-C4, No difference in pattern separation between rewarded $\left(S^{+}\right)$and unrewarded $\left(S^{-}\right)$mitral cell ensembles in the OBs of the drug and saline groups.

With 17 blocks of extensive training, the drug group was discriminating between $\mathrm{S}^{+}$and $\mathrm{S}^{-}(88 \pm 1.22 \%$ vs $92 \pm 3 \%$ in the saline group, $n=5, t=1.23, p=0.25$; Fig. 1C1) and the OLR in the drug group was larger $(45.72 \pm 0.88)$ and not different from that in the saline group ( $43.07 \pm 2.78 \%, n=5, t=0.91, p=0.39$; Fig. 1C2,C3). The distribution of $\mathrm{Arc}^{+}$cells (total, double, single) was similar in both groups (Fig. 1C4). OB adrenergic blockade compromised the natural course of enhanced stability of aPC representations with training and made discrimination of similar odors more challenging.

Pattern separation in the aPC was also examined in rats that underwent six blocks of training (Fig. 1D1). Arc expression was visualized after exposure to $\mathrm{S}^{+}$then $\mathrm{S}^{-}$. Here, OLR indexes the overlap between two different odor representations. The OLR was significantly smaller in the saline group $(16.78 \pm 1.39 \%, n=$
5) than in the drug group $\left(28.56 \pm 0.96 \% ; t=6.97, p=1.16 \mathrm{E}^{-4}\right.$; Fig. 1D2,D3), suggesting pattern separation in the saline, but not the drug, group. Correspondingly, there were more double $\mathrm{Arc}^{+}$ cells in the drug group $(3.61 \pm 0.50 \%)$ than in the saline group $(1.76 \pm 0.21 \%, n=5, t=3.39, p=0.009$; Fig. 1D4). Inability to discriminate similar odors after six blocks of training was accompanied by a lack of pattern separation and rewarded odor stability in the drug group aPC odor ensembles.

APC adrenoceptor blockade prevents similar odor discrimination and impairs reliability of odor representations in the $\mathrm{OB}$

The role of aPC adrenoceptors in odor discrimination learning has not been studied. Here, we infused adrenoceptor blockers into aPC before training and infused rats were unable to discrim- 
inate the similar odors despite extensive training (Fig. 2B1,C1). At the $17^{\text {th }}$ block, the drug group is unable to discriminate ( $55 \pm$ $4.2 \%, n=5, t=9.07, p=1.75 \mathrm{E}^{-5}$; Fig. $2 \mathrm{Cl}$ ), whereas the saline group is highly successful ( $94 \pm 1 \%$ ), having reached discrimination criterion at 6 blocks. This is the first evidence that aPC adrenoceptors are critical for similar odor discrimination learning. We also tested a subset of these rats for their memory of the earlier orange and peppermint discrimination. Recall and discrimination of these distinct odors was not affected by aPC adrenoceptor blockade (data not shown).

Arc visualization in the $\mathrm{OB}$ after odor discrimination training with aPC adrenoceptor blockade revealed differences in both mitral and granule cell ensemble representations to the rewarded odor. The OLR of mitral cell ensembles to the rewarded odor in the saline group (35.69 $\pm 3.72 \%, n=4)$ was larger than in the drug group (19.58 $\pm 1.55 \% ; t=4.00, p=0.007$, Fig. 2B2,B3). Double $\mathrm{ArC}^{+}$cells were fewer in the drug group $(1.26 \pm 0.11 \%)$ than in the saline group $(3.00 \pm 0.36 \%, n=4, t=4.60, p=0.004$; Fig. 2B4). Similarly, the OLR of granule cell ensembles to the rewarded odor was larger in the saline group $(38.72 \pm 2.96 \%)$ than the drug group $(17.36 \pm 0.55 \%, n=4 ; t=7.08, p=3.97$ $\mathrm{E}^{-4}$; Fig. 2B2,B5). This was again due to fewer double $\mathrm{Arc}^{+}$cells in the drug group $(0.94 \pm 0.13 \%$ drug group vs $2.96 \pm 0.40$ saline group, $n=4, t=4.86, p=0.003$; Fig. 2B6). Together, aPC adrenergic disruption during similar odor discrimination training impairs the reliability of neuronal representations to the rewarded odor in the OB.

Finally, we tested whether aPC adrenergic blockade affects pattern separation of the $\mathrm{OB} \mathrm{S}^{+}$and $\mathrm{S}^{-}$ensembles. This was performed after 17 blocks of training (Fig. 2C1). There were no differences in the OLR of the two ensembles in the two groups (16.84 \pm 1.63 in the saline group vs $12.58 \pm 2.41 \%$ in the drug group; $n=4, t=1.46, p=0.18$; Fig. 2C2,C3). There was also no difference in the distribution pattern of $\mathrm{Arc}^{+}$ neurons (Fig. 2C4).

\section{Discussion}

\section{Blockade of $\mathrm{OB}$ adrenoceptors slows similar odor} discrimination and the stabilization of reward odor encoding in aPC

Rats with OB blockade of adrenoceptors did not learn the similar discrimination in six blocks of training, but did reach criterion after 14 blocks. After six blocks, the rewarded odor representation in aPC for saline-infused rats revealed increased stability relative to that in OB-NE blockade rats (OLR $38 \%$ vs $22 \%$ ). When the drug group reached criterion, there was no longer a difference in OLR from the saline group; both showed increased stability. Increased stability of cortical motor (Peters et al., 2014; Cao et al., 2015) and sensory (Shakhawat et al., 2014a; Shakhawat et al., 2014b; Poort et al., 2015) representations with learning appears to be a general feature of learning-induced network change. Ensemble sizes were similar to previous reports for aPC $(\sim 4-5 \%$; Shakhawat et al., 2014a).

Critically for this discrimination task, pattern separation in aPC for the saline-infused group (OLR S $\left.{ }^{+} / \mathrm{S}^{-} 17 \%\right)$ was significantly greater after six blocks than for the drug-infused group $(29 \%)$. Pattern separation in aPC ensembles has also been reported after similar discrimination learning (Chapuis and Wilson, 2012; Shakhawat et al., 2014a).

\section{Blockade of adrenoceptors in aPC prevents similar odor discrimination and stabilization of reward odor encoding in $\mathrm{OB}$}

Adrenergic antagonists in aPC prevented successful discrimination learning even after 17 blocks of training. At six blocks, salineinfused rats reached criterion and had greater overlap in rewarded odor ensembles for both mitral cells $(\sim 36 \%)$ and granule cells $(\sim 39 \%)$. This is similar to OB changes in odor ensemble encoding with preference training in the rat pup (Shakhawat et al., 2014b). Ensemble size (7.5\%) was also similar for pups and adults. A parsimonious explanation of the ensemble changes is that activated mitral cells recruit their associated granule cells.

Pattern separation in $\mathrm{OB} \mathrm{Arc}{ }^{+}$ensembles was not seen during this task. Whether the $\mathrm{OB}$ contributes to pattern separation is still under debate (Sahay et al., 2011).

\section{Neural constraints on similar odor discrimination learning}

Learning increases in the OLR of rewarded odors (Shakhawat et al., 2014a; Shakhawat et al., 2014b), but not unrewarded odors (Shakhawat et al., 2014b), reveals the importance of reduced variability in encoding survival-relevant odors.

The present data suggest that aPC-NE is required for difficult odor discrimination learning. NE enhances the signal-to-noise ratio of the afferent inputs to aPC (Hasselmo et al., 1997). The data also imply that feedback from the learned aPC representation is necessary to the development of stability in the $\mathrm{OB}$ ensemble. Odor/reward associations are slowed when centrifugal feedback to the bulb is transected (Kiselycznyk et al., 2006). Blockade of OB NE does not prevent stability or pattern separation changes in aPC ensembles, but slows their appearance. This result is consistent with evidence that OB NE facilitates similar odor discriminations (Doucette et al., 2007; Mandairon et al., 2008).

The obligatory role of aPC NE for the acquisition of similar odor discriminations was unexpected. Pattern separation in aPC is likely fundamental to successful learning. Pattern separation requires the dissociation of ensembles either through enhancement of inhibitory processes or a weakening of connections. The long training required for separation of similar odor representations might relate to competing demands for strengthening rewarded representations and weakening overlap to facilitate discrimination. Simple discrimination only requires a strengthening of connections (Shakhawat et al., 2014a). NE facilitates inhibition and supports LTD and LTP; in the latter case, the implicated receptors differ (Kirkwood et al., 1999). Selective antagonism in aPC may help to reveal the mechanisms implicated in odor pattern separation.

Another requirement for discriminating similar odors is neural space. Odor objects activate similar-sized ensembles. With less overlap, more neurons are needed for odor differentiation. This is consistent with human evidence reporting more discriminable episodic memories in individuals with larger relevant neural space (Chadwick et al., 2014).

\section{References}

Bouret S, Sara SJ (2002) Locus coeruleus activation modulates firing rate and temporal organization of odour-induced single-cell responses in rat piriform cortex. Eur J Neurosci 16:2371-2382. CrossRef Medline

Boyd AM, Kato HK, Komiyama T, Isaacson JS (2015) Broadcasting of cortical activity to the olfactory bulb. Cell Rep 10:1032-1039. CrossRef Medline

Cao VY, Ye Y, Mastwal S, Ren M, Coon M, Liu Q, Costa RM, Wang KH (2015) Motor learning consolidates Arc-expressing neuronal ensembles in secondary motor cortex. Neuron 86:1385-1392. CrossRef Medline 
Chadwick MJ, Bonnici HM, Maguire EA (2014) CA3 size predicts the precision of memory recall. Proc Natl Acad Sci U S A 111:10720-10725. CrossRef Medline

Chapuis J, Wilson DA (2012) Bidirectional plasticity of cortical pattern recognition and behavioral sensory acuity. Nat Neurosci 15:155-161. Medline

de Almeida L, Reiner SJ, Ennis M, Linster C (2015) Computational modeling suggests distinct, location-specific function of norepinephrine in olfactory bulb and piriform cortex. Front Comput Neurosci 9:73. Medline

Doucette W, Restrepo D (2008) Profound context-dependent plasticity of mitral cell responses in olfactory bulb. PLoS Biol 6:e258. CrossRef Medline

Doucette W, Milder J, Restrepo D (2007) Adrenergic modulation of olfactory bulb circuitry affects odor discrimination. Learn Mem 14:539-547. CrossRef Medline

Doucette W, Gire DH, Whitesell J, Carmean V, Lucero MT, Restrepo D (2011) Associative cortex features in the first olfactory brain relay station. Neuron 69:1176-1187. CrossRef Medline

Escanilla O, Arrellanos A, Karnow A, Ennis M, Linster C (2010) Noradrenergic modulation of behavioral odor detection and discrimination thresholds in the olfactory bulb. Eur J Neurosci 32:458-468. CrossRef Medline

Franks KM, Isaacson JS (2006) Strong single-fiber sensory inputs to olfactory cortex: implications for olfactory coding. Neuron 49:357-363. CrossRef Medline

Hasselmo ME, Linster C, Patil M, Ma D, Cekic M (1997) Noradrenergic suppression of synaptic transmission may influence cortical signal-tonoise ratio. J Neurophysiol 77:3326-3339. Medline

Kirkwood A, Rozas C, Kirkwood J, Perez F, Bear MF (1999) Modulation of long-term synaptic depression in visual cortex by acetylcholine and norepinephrine. J Neurosci 19:1599-1609. Medline

Kiselycznyk CL, Zhang S, Linster C (2006) Role of centrifugal projections to the olfactory bulb in olfactory processing. Learn Mem 13:575-579. CrossRef Medline

Mandairon N, Peace S, Karnow A, Kim J, Ennis M, Linster C (2008) Noradrenergic modulation in the olfactory bulb influences spontaneous and reward-motivated discrimination, but not the formation of habituation memory. Eur J Neurosci 27:1210-1219. CrossRef Medline

McLean JH, Shipley MT, Nickell WT, Aston-Jones G, Reyher CK (1989) Chemoanatomical organization of the noradrenergic input from locus coeruleus to the olfactory bulb of the adult rat. J Comp Neurol 285:339349. CrossRef Medline

Morrison GL, Fontaine CJ, Harley CW, Yuan Q (2013) A role for the anterior piriform cortex in early odor preference learning: evidence for mul- tiple olfactory learning structures in the rat pup. J Neurophysiol 110: 141-152. CrossRef Medline

Otazu GH, Chae H, Davis MB, Albeanu DF (2015) Cortical feedback decorrelates olfactory bulb output in awake mice. Neuron 86:1461-1477. CrossRef Medline

Peters AJ, Chen SX, Komiyama T (2014) Emergence of reproducible spatiotemporal activity during motor learning. Nature 510:263-267. CrossRef Medline

Poo C, Isaacson JS (2011) A major role for intracortical circuits in the strength and tuning of odor-evoked excitation in olfactory cortex. Neuron 72:41-48. CrossRef Medline

Poort J, Khan AG, Pachitariu M, Nemri A, Orsolic I, Krupic J, Bauza M, Sahani M, Keller GB, Mrsic-Flogel TD, Hofer SB (2015) Learning enhances sensory and multiple non-sensory representations in primary visual cortex. Neuron 86:1478-1490. CrossRef Medline

Rinberg D, Koulakov A, Gelperin A (2006) Sparse odor coding in awake behaving mice. J Neurosci 26:8857-8865. CrossRef Medline

Sahay A, Wilson DA, Hen R (2011) Pattern separation: a common function for new neurons in hippocampus and olfactory bulb. Neuron 70:582-588. CrossRef Medline

Shakhawat AM, Harley CW, Yuan Q (2014a) Arc visualization of odor objects reveals experience-dependent ensemble sharpening, separation, and merging in anterior piriform cortex in adult rat. J Neurosci 34:1020610210. CrossRef Medline

Shakhawat AM, Gheidi A, Hou Q, Dhillon SK, Marrone DF, Harley CW, Yuan Q (2014b) Visualizing the engram: learning stabilizes odor representations in the olfactory network. J Neurosci 34:15394-15401. CrossRef Medline

Shipley MT, Ennis M (1996) Functional organization of olfactory system. J Neurobiol 30:123-176. Medline

Stettler DD, Axel R (2009) Representations of odor in the piriform cortex. Neuron 63:854-864. CrossRef Medline

Wachowiak M, Economo MN, Díaz-Quesada M, Brunert D, Wesson DW, White JA, Rothermel M (2013) Optical dissection of odor information processing in vivo using GCaMPs expressed in specified cell types of the olfactory bulb. J Neurosci 33:5285-5300. CrossRef Medline

Wilson DA, Sullivan RM (1994) Neurobiology of associative learning in the neonate: early olfactory learning. Behav Neural Biol 61:1-18. CrossRef Medline

Wilson DA, Sullivan RM (2011) Cortical processing of odor objects. Neuron 72:506-519. CrossRef Medline

Yuan Q, Shakhawat AM, Harley CW (2014) Mechanisms underlying early odor preference learning in rats. Prog Brain Res 208:115-156. CrossRef Medline 